\title{
A New Alternative Thinner in the Drilling Fluid System
}

\author{
Wissam H. AL-Hashimi, \\ Baghdad Oil Training Institute (BOTI)
}

\section{Abstract}

The most important constituent of drilling operation success is keeping the drilling fluid rheological properties within a certain limit to maintain continuing their functions in a good manner. To achieve that, the drilling mud system needs continuous and direct supervision such as measuring its rheological properties and treating any deviation in their values. Viscosity is the most important property in hydraulic program success due to its direct relation with bottom hole cleaning during drilling, thus related with the drilling rate, so this property should be kept basically to ensure bottom hole cleaning and high drilling rate at the same time.

Some chemicals such as thinner should be added to the mud system to keep both viscosity and other properties within certain standards and required limits; these materials have a high cost, increasing both the metric cost and the final cost of such well.

The aim of this research is to test the physical and chemical properties for a local material, as a thinner, which tends to decrease the rheological properties of drilling mud .Thirty nine samples of different types of drilling mud are tested with both the native and foreign imported materials. The results for both additive materials are compared and concluded that the local thinner has the same trend with the imported material to a certain limit.

\section{Introduction}

Basically, the drilling operations depend on two factors, time and cost. The drilling engineers work hard to reduce the drilling cost by using economic drilling program.

The drilling program includes all the ways that lead to decrease both the time and cost effectively through increasing the drilling rate which depends mainly on the drilling mud properties, weight on bit, and the rotary speed.

In Iraq, the chemicals which are added to the drilling fluids lead to increase the drilling cost due to their high price and continuous requirement to control the rheological properties.

Our objective is finding out an alternative thinner instead of conventional thinner to reduce the rheological properties and thus, decreasing the cost of well drilling. The researcher follows both the theoretical way depending on the trusted references in drilling fluids and experimental way through laboratory testing for three types of drilling fluids( fresh water, salt water and lime mud) 
using two types of thinner, the first one is ferrochrome lignosulphonate and the second one is a local thinner. The chemical analysis for both types of thinner are studied

\section{Functions of drilling mud}

Drilling mud is the most important factor for the success of drilling operation. The target which represents the oil reservoir could not be reached without using standard and conventional drilling mud properties. The functions of the drilling mud are:-

1-Controlling the formation pressure which may have different fluids.

2-Cleaning the well through lifting the cuttings to the surface.

3-Consolidating the wall of the hole through forming a thin mud cake.

4-Cooling and lubricating the bit.

5-Facilitating cementing and completion operations.

6-Controlling corrosion in acceptable limit.

7-Transmitting hydraulic energy to the tools and bit. [6]

8-Providing geological information. [1]

\section{Drilling fluid characteristics}

1-Suitable pressure requirement to circulate drilling mud with recommended quantity and velocity.

2-Mininmum effects on the production zone.

3- Doesn't corrode or cause excessive wear of drilling equipment.

4-Doesn't reduce penetration rate. [6]

\section{Drilling fluid ingredients}

1-The liquid phase which include both types of water (fresh and brine) and crude oil.

2-Solid phase:-subdivided into:

A- Interactive solids: they can interact with the other drilling fluid ingredients such as clay and salts. They can be controlled by adding chemicals to the drilling fluid.

B-Inert solids: such as Barite which is used to increase mud weight.

3- Chemicals: they can be used to maintain drilling fluid properties within suitable limit. [6] 


\section{The rheological properties of the drilling fluids}

They are related with the flowing of the drilling fluid in the mud system. They include the following:-

1- VISCOSITY: It can be defined as a fluid resistance to flow. It is measured by Marsh funnel or rotational viscometer. The measuring unit is centipoise.

The viscosity is created depending on two components:

A-Plastic viscosity: it results from mechanical friction force which happens among

The solids in the drilling fluid, solids and surrounding liquid phase and the liquid phase surfaces. [6]

The plastic viscosity depends on the concentration, shapes, and the volume of the solids. Mathematically, the plastic viscosity can be calculated by following formula:-

$\mu \mathrm{p}=\theta 600-\theta 300$ where:

$\mu \mathrm{p}=$ plastic viscosity $(\mathrm{C} . \mathrm{P}), \theta 600=$ Dial reading at $600 \mathrm{RPM}\left(\mathrm{Ib} \backslash 100 \mathrm{ft}^{2}\right), \theta 300=$ Dial reading at $300 \mathrm{RPM}\left(\mathrm{Ib} \backslash 100 \mathrm{ft}^{2}\right)$

B-Yield point: The amount of electrochemical attracting forces between the particles during the flow due to the negative and positive charges on or near the particle surfaces. ${ }^{[6]}$

The yield point depends on the characteristics of particles surfaces, concentration and presence of ions in drilling fluids. It can be calculated by the following formula:

$\mathrm{Yp}=\theta 300-\mu \mathrm{p}$ where:Yp=yield point $\left(\mathrm{Ib} \backslash 100 \mathrm{ft}^{2}\right), \theta 300=$ Dial reading at $300 \mathrm{RPM}(\mathrm{Ib} \backslash 100 \mathrm{ft}$ $\left.{ }^{2}\right), \mu \mathrm{p}=$ plastic viscosity (C.P).

There are other types of viscosity:-

1-Apparent viscosity: It results from the combined effect for both plastic viscosity and yield point, it can be calculated by the following formula:-

$\mu \mathrm{a}=\theta 600 \backslash 2$

where:- $\mu \mathrm{a}=$ Apparent viscosity (C.P), $\theta 600=$ Dial reading at $600 \mathrm{RPM}\left(\mathrm{Ib} \backslash 100 \mathrm{ft}^{2}\right.$ ).

2-Effective viscosity: - It is defined as equivalent viscosity, it takes into consideration hole diameter, drill string diameter in addition to plastic viscosity and yield point. It can be calculated by the following formula ${ }^{[3]}:-$

$\mu \mathrm{e}=\mu \mathrm{p}+(6.65 \mathrm{Yp}(\mathrm{dH}-\mathrm{dP}) \backslash \mathrm{v})$ where:-

$\mu \mathrm{e}=$ effective viscosity (C.P), $\mu \mathrm{p}=$ plastic viscosity (C.P),

$\mathrm{Yp}=$ Yield point $\left(\mathrm{Ib} \backslash 100 \mathrm{ft}^{2}\right), \mathrm{dH}=$ Hole diameter (inch), $\mathrm{dP}=$ Drill string diameter(inch) 
2-Gel strength: - The measure of attractive forces between particles in the static state. It also represents the shear stress necessary to start the fluid flowing.

The units of gel strength are $\left(\mathrm{Ib} \backslash 100 \mathrm{ft}^{2}\right)$ and measured by rotational viscometer at 3 RPM. ${ }^{[6]}$ 3-Alkalinity: - It is defined as the negative logarithm of positive hydrogen ion concentration. $\mathrm{PH}=\log \left(\mathrm{H}^{+}\right) \quad$ where:-

$\mathrm{PH}=$ Alkalinity

$\left(\mathrm{H}^{+}\right)=$Hydrogen ion.

It can be measured by digital PH meter, or special test papers. [6]

4-FILTRATION:-Percolation of drilling fluid filtrate into the permeable zone due to the pressure difference that results in settling part of solid phase on the wall, thus a film of mud cake can be formed. The filtration is measured by API filter press and the measurement unit is $\mathrm{cm}^{3} \backslash 30$ $\min .[6]$

\section{Types of drilling fluids [6]}

There are several types of drilling fluids classified depending on the main liquid phase:-

\section{1-Water base mud}

In this type, water represents the liquid phase and it is subdivided into:-

A-Fresh water mud

B-Salt water mud

\section{2-Inhibitive mud}

This type of mud has a little effect on the penetrated sections through resisting solids hydrates; also this type resists clay hydration and keeps the well stable.

There are two types of inhibitive mud:-

A-Calcium treated mud

a- Lime base mud

b- Gypsum mud

B-Ferro chrome Lignosulphonate treated mud 


\section{3-Emulsion mud}

It includes both oil and water liquids and it can be subdivided into:-

A-Oil in water emulsion mud

B-Water in oil emulsion mud

\section{$\underline{4-O i l ~ B a s e ~ m u d ~}$}

The base liquid in this type of mud is oil. It contains about (5-7\%) of water that includes dissolved calcium in emulsion state.

\section{5-Modern drilling mud}

Known as low solids mud, such as polymers which are characterized by high cost because of their synthetic contents.

\section{Chemicals used in the drilling fluid system}

It is important to maintain the rheological properties of any drilling fluid at a certain limit. To achieve that, chemicals are used to increase or decrease these properties according to hole condition. They are known as thinners and subdivided into the following:-

\section{1-Non organic thinners}

One of the most conventional compounds of this type is phosphates which are used with water base mud in normal temperature gradients to control the rheological properties of the drilling fluids.

There are four types of phosphates:-

A-Sodium acid pyrophosphate $\left(\mathrm{Na}_{2} \mathrm{H}_{2} \mathrm{P}_{2} \mathrm{O}_{4}\right)$

B-Sodium hexameta phosphate $\left(\mathrm{NaPO}_{3}\right)$

C- Sodium tetra phosphate $\left(\mathrm{Na}_{6} \mathrm{PO}_{4} \mathrm{O}_{13}\right)$

D-Tetra sodium pyrophosphate $\left(\mathrm{Na}_{4} \mathrm{P}_{2} \mathrm{O}_{7}\right)$ [4] 


\section{2-Organic thinners}

It can be subdivided into:-

A-Li gnosulphonate:-A complex compound extracted from special plants, it is prepared synthetically by lignin compounds interaction with acid sulfite, calcium acid sulfite or sodium acid sulfite.

These compounds are used as thinners and known as ferro chrome lignosulphonate.

\section{B-Lignin compounds}

They are natural compounds whose internal compositions are unknown. They can be classified as acids. These compounds are produced by plants degradation as dark brown powder. ${ }^{[4]}$

\section{C-Tannin compounds}

The word tannin is a collective term for a group of complex astringent substances made of carbon, hydrogen, oxygen, and in some cases containing small amounts of nitrogen and phosphorous.

Tannins are broadly classified chemically as hydrolysable tannins consisting esters of one or more polyphenolic acids such as Gallic acid.

Tannins occur in many plants and are extracted from bark, wood, and fruit.

Sources include the barks of wattle, mangrove and eucalyptus, the woods of quebracho and chestnut. [5]

\section{The local thinner, chemical and physical tests}

The local thinner is characterized by its low cost, cheap and attainable. It is found in roots, stems ,and fruits such as gall oak ,quebracho ,sumac ,mimosa ,these plants are widely spread in different countries over the world especially in south Africa, Argentina ,and Iraq .The local thinner contains about $25-28 \%$ of organic material known as tannins and some compounds such as punicalin (Grananatine D) and punicalagin (Grananatine C). The tannin decreases the rheological properties(plastic viscosity, yield point and gel strength) of the drilling fluid due to presence of Gallic acid which result from tannin analysis in the water as shown later.

Tannin is an organic complex compound and dark color plants. It dissolves in water, alcohol and glycerin. This compound is produced by biochemical process of the plants. The internal composition contains carbon, oxygen, and sometimes impurities like nitrogen and phosphors. ${ }^{[3]}$ The chemical structure of tannin is complex but it is such various benzene acid hydrates, it a mixture of five molecules of digallic acid with one molecule of glucose. In degradation in water, 
the digallic acid transforms to Gallic acid which tends to decrease the rheological properties of the drilling fluids as shown below: - [5]

$$
{ }_{14} \mathrm{H}_{10} \mathrm{O}_{9}+\mathrm{C}_{6} \mathrm{H}_{12} \mathrm{O}_{6} 5 \mathrm{C} \longrightarrow 5 \mathrm{H}_{2} \mathrm{O}+5\left(\mathrm{C}_{14} \mathrm{H}_{9} \mathrm{O}_{9}\right) \mathrm{C}_{6} \mathrm{H}_{7} \mathrm{O}
$$

The tannin is also used in the taw and manufactured leather.

\section{Chemical tests}

1-Detection of tannin ratio

It was conducted in analysis laboratory in Baghdad Oil Training Institute; it has been found that the tannin ratio is $28 \%$ by the following process:

$1 \mathrm{gm}$ of native thinner is dissolved in $40 \mathrm{ml}$ of boiled water, $0.1 \mathrm{gm}$ of cupric acetate is added and the mixture is re boiled and then filtrated with filter paper. The paper is dried with $0.1 \mathrm{gm}$ of nitric acid. The precipitation is burned and the weight of Cuo (Copper oxide) is taken. The tannin ratio is calculated by the following formula: ${ }^{[2]}$

Cuo*1.45=tannin $\%$

$0.194 * 1.45=28 \%$.

The following tests were done at the laboratories of Petroleum Research and Developing Centre (PRDC) (See Appendix B).

2-Detection of both cooper and iron ratio in the local thinner by ultra violet tests. It has been found that the $\mathrm{Cu}=0.095$ and $\mathrm{Fe}=0.06$.

3-Detection of real density

It has been found that the real density is $1.318 \mathrm{gm} / \mathrm{cc}$.

4-Fourier transform infrared test.

It has been found that the local thinner contains hydroxyl, Easter, and benzene groups in addition to aromatic compounds.

\section{Physical tests}

In order to detect the effect of local thinner on the rheological properties of the mud, three types of drilling fluid are tested with local and foreign thinners.

The tests results are compared and discussed, the foreign thinner used in these tests is ( $\mathrm{FCl})$ which is widely used in Iraqi fields. 


\section{Results and discussions}

1-For fresh water mud

Numbers of samples of this type of mud are prepared. They contain $22.5 \mathrm{gm}$ of Bentonite with $350 \mathrm{ml}$ distilled water, the mixtures are left 24 hours for hydration, the $\mathrm{FCl}$ thinner is added with weights $(0.5,1,1.5,2,2.5,3)$ gm respectively, then the samples are mixed for 20 minutes before the tests process are run at room temperature. The tested properties are apparent viscosity, plastic viscosity, yield point, filtration, and the alkalinity of the filtrate. The same procedures are repeated again with the local thinner; their results are compared and discussed.

Figures $(1,2)$ (tables $1 \& 2$ in Appendix A) show the effect of both $\mathrm{FCl}$ and local thinners on the rheological behavior for this type of mud.

\section{A- $\mathrm{FCl}$ thinner}

It is noticed the apparent viscosity, yield point, and gel strength decreased clearly, while the plastic viscosity values were almost constant (9-10) centipoise(C.P).

The filtration rate values decreased gradually by increasing weight of added thinner, the alkalinity of filtrate ranged (8.5-9.8).

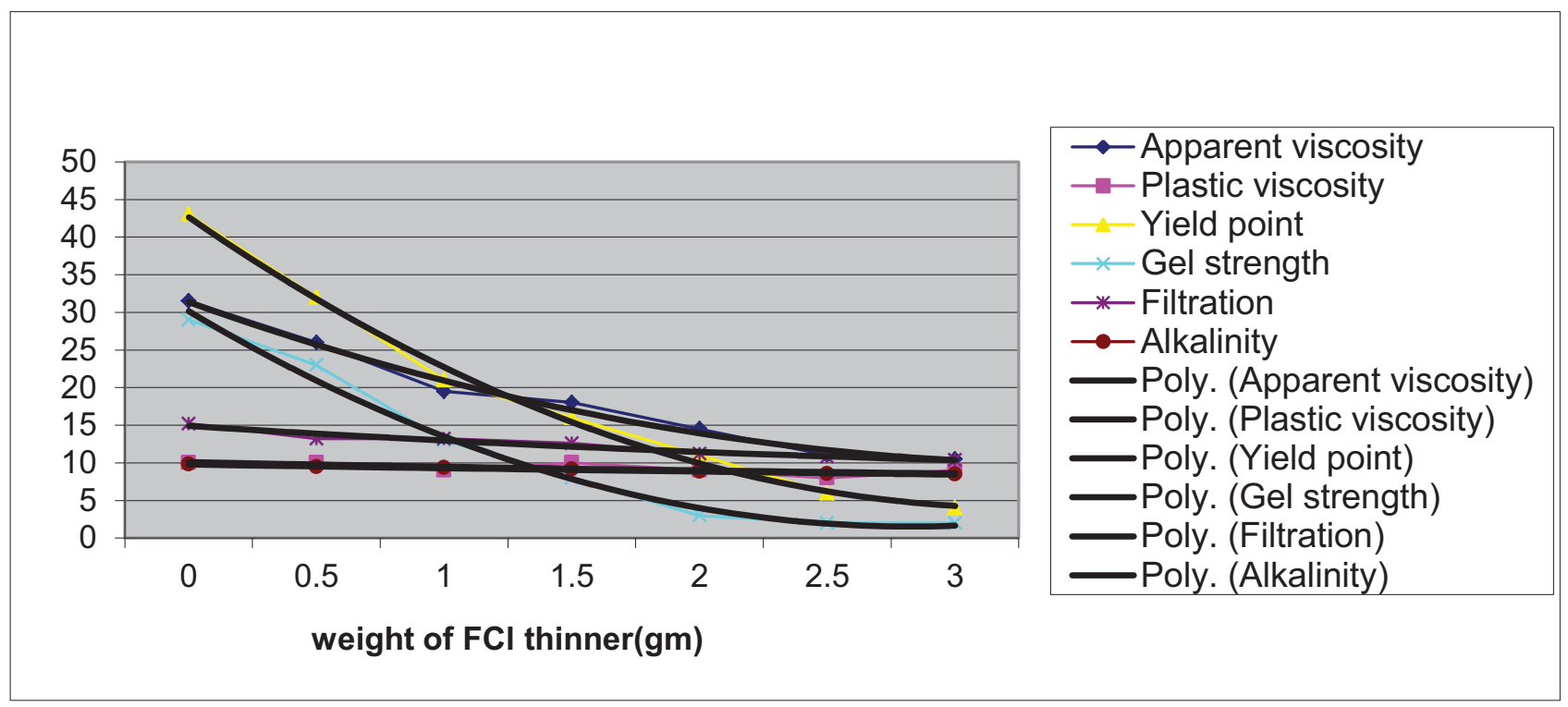

Fig.(1) Effect of FCl thinner on the rheological behavior of fresh water mud. 


\section{B- Local thinner}

It is noticed that apparent viscosity, yield point, and gel strength decreased clearly to the weight of $1 \mathrm{gm}$ of the added thinner, and then the values were almost 30, 31 C.P for apparent viscosity and 40-43 (lb $\backslash 100 \mathrm{ft}^{2}$ ) for yield point. At weight more than $1 \mathrm{gm}$ of the added thinner both plastic viscosity and gel strength values remain constant.

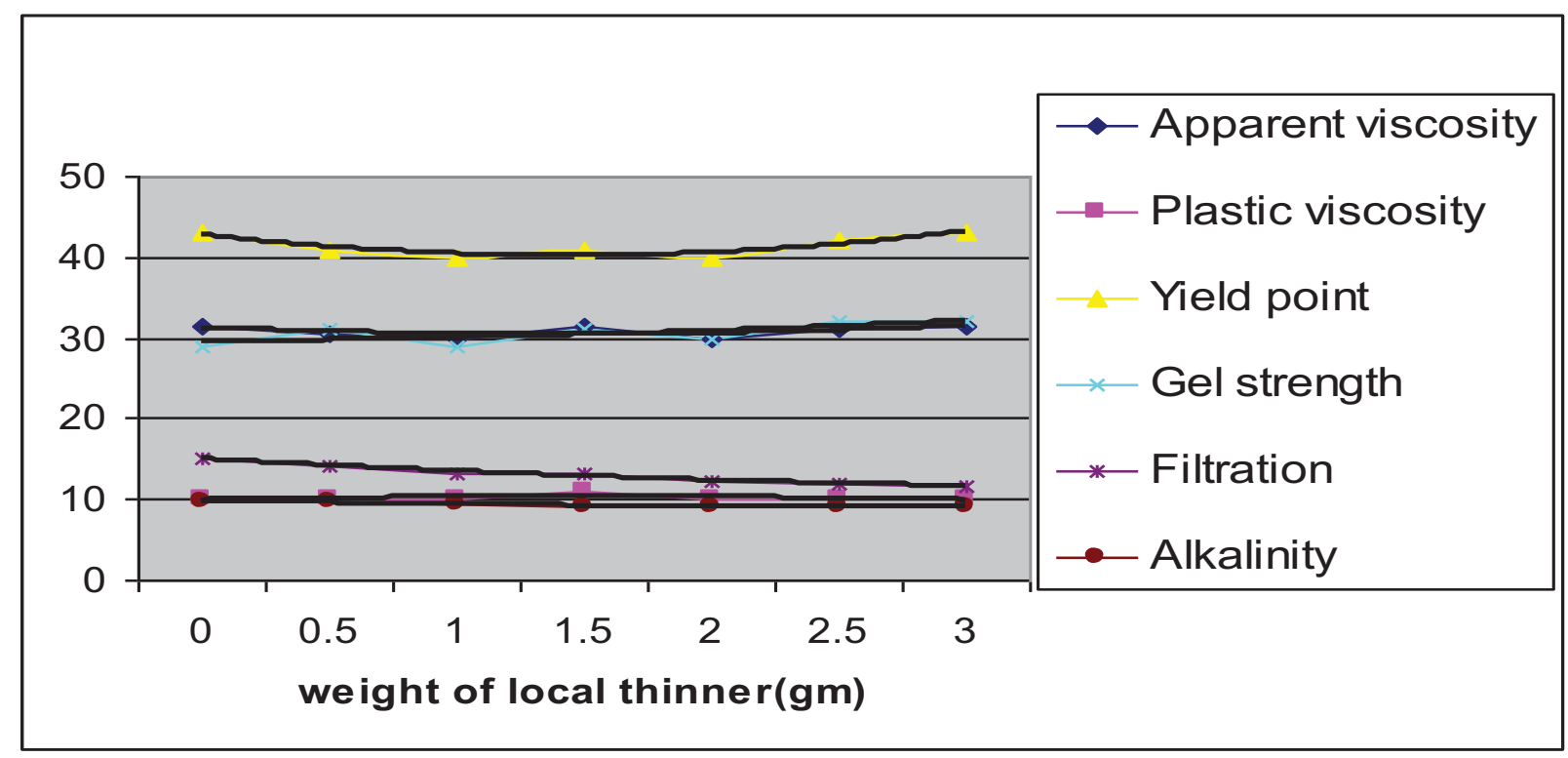

Fig.(2) Effect of local thinner on the rheological behavior of fresh water mud.

The filtration rate values decreased gradually to $11.6 \mathrm{~cm}^{3} \backslash 30 \mathrm{Min}$. With increased weight of added thinner, the alkalinity of filtrate ranged (9-9.8).

\section{2-For salt water mud}

Number of samples of this type of mud are prepared. They contain 22.5 gm of Bentonite with $350 \mathrm{ml}$ tap water with $4 \% \mathrm{Nacl}$ dissolved in water. The mixtures are left 24 hours for hydration, the $\mathrm{FCl}$ thinner is added with weights $(0.5,1,1.5,2,2.5,3)$ gm respectively, then the samples are mixed for 20 minutes before the tests process are run at room temperature. The tested properties are apparent viscosity, plastic viscosity, yield point, filtration, and the alkalinity of the filtrate. The same procedures are repeated again with the local thinner; their results are compared and discussed.

Figs (3 and 4)(tables 3 and 4 in Appendix A) show the effect of both $\mathrm{FCl}$ and local thinners on the rheological behavior for this type of mud. 


\section{A- FCl thinner}

It is noticed that both apparent viscosity, yield point decreased clearly to the weight $1 \mathrm{gm}$ of the added thinner ,after that, the apparent viscosity ranged (9-21)C.P while the yield point values ranged (32-34) $\left(\mathrm{lb} \backslash 100 \mathrm{ft}^{2}\right)$.

The plastic viscosity values remain nearly (4-6) C.P and the filtration rate values ranged (47.854) $\mathrm{Cm}^{3} \backslash 30$ Min. The alkalinity values rated (8.9-7.73).

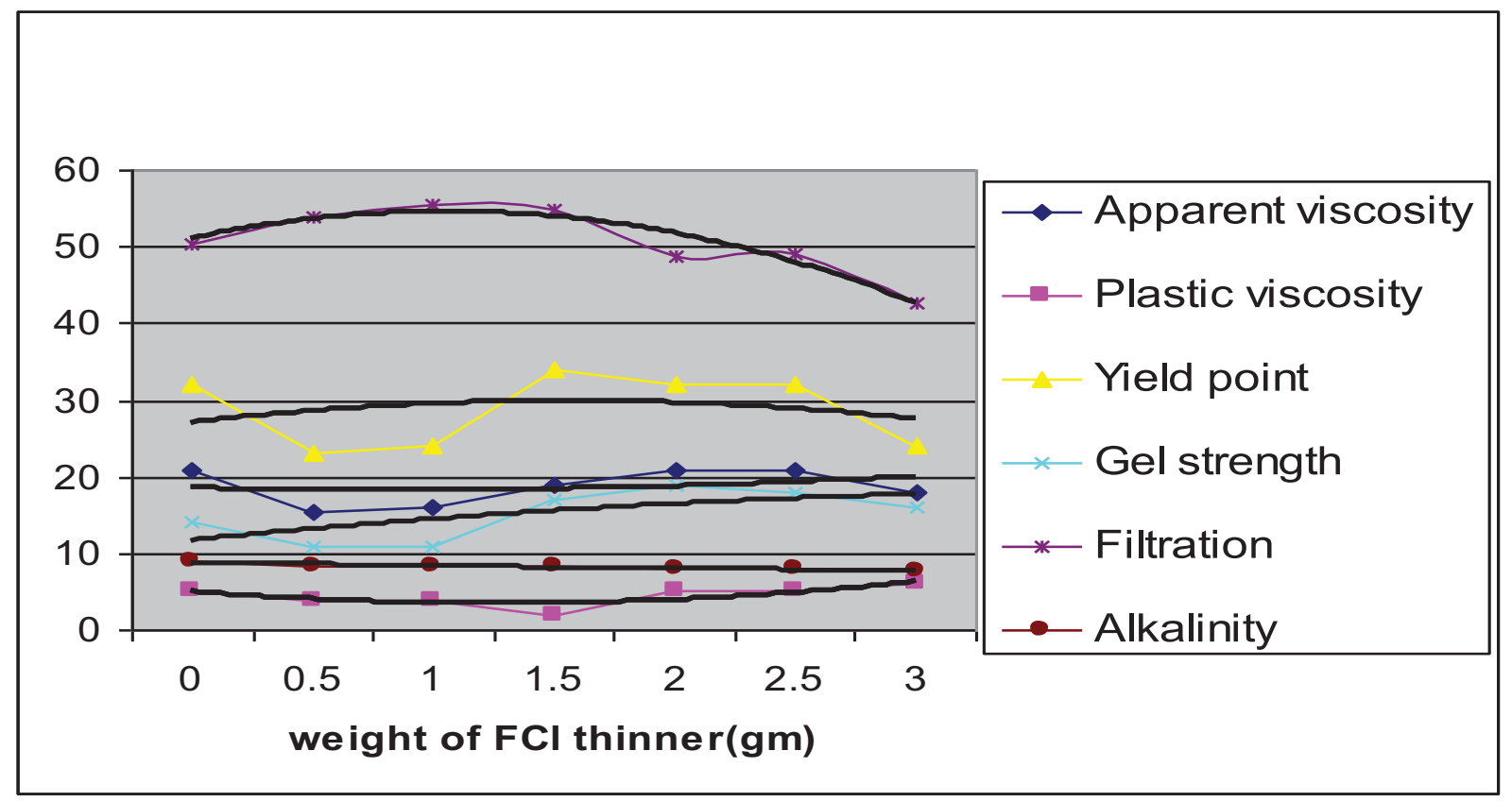

Fig.(3) Effect of FCl thinner on the rheological behavior of salt water mud.

\section{B- Local thinner}

It is noticed that both apparent viscosity, yield point decreased clearly to weight $1.5 \mathrm{gm}$ of the added thinner, and then these properties remain almost constant (17 C.P for apparent viscosity and (24-26) $1 b \backslash 100 \mathrm{ft}^{2}$ for yield point). The plastic viscosity ranged (3-5) C.P while the gel strength ranged (12-14) $l b \backslash 100 \mathrm{ft}^{2}$.

The filtration rate values decreased gradually to $45.4 \mathrm{~cm}^{3} \mid 30$ Min. The alkalinity of filtrate decreased to stabilize at 8.24. 


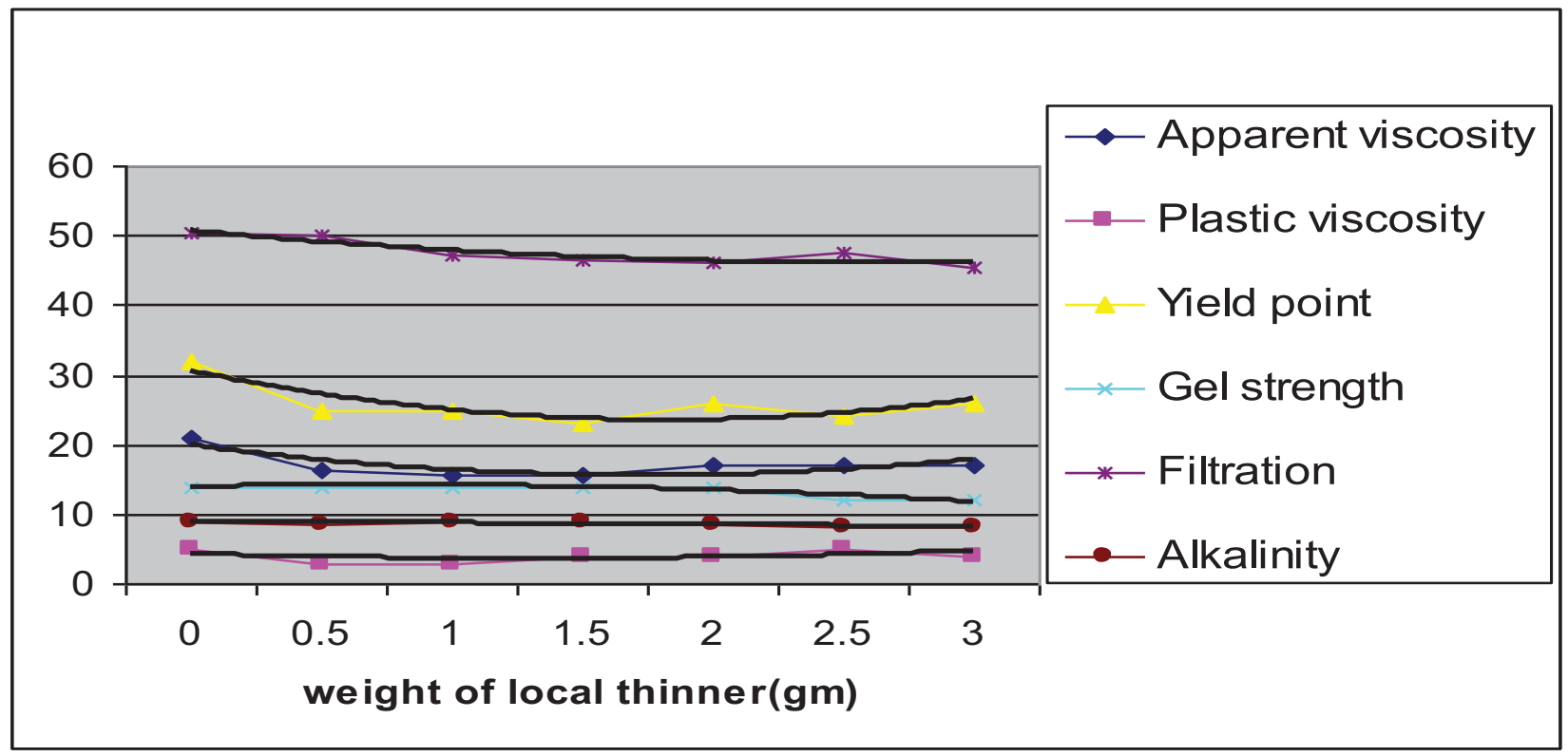

Fig.(4) Effect of local thinner on the rheological behavior of salt water mud.

\section{3-For lime mud}

Number of samples of this type of mud are prepared. They contain $22.5 \mathrm{gm}$ of Bentonite with $350 \mathrm{ml}$ tap water, and $5 \mathrm{gm}$ of lime (Cao), the mixtures are left 24 hours for hydration, the $\mathrm{FCl}$ thinner is added with weights $(0.5,1,1.5,2,2.5,3)$ gm respectively, then the samples are mixed for 20 minutes before the tests process are run at the room temperature., the tested properties are apparent viscosity, plastic viscosity, yield point, filtration, and the alkalinity of the filtrate. The same procedures are repeated again with the local thinner; their results are compared and discussed.

Figures ( $5 \& 6$ ) (tables 5 and 6 in Appendix A) show the effect of both $\mathrm{FCl}$ and local thinners on the rheological behavior for this type of mud.

\section{A- FCl thinner}

It is noticed that the apparent viscosity, yield point , and gel strength decreased clearly to the weight $2.5 \mathrm{gm}$ of the added thinner, after that, the apparent viscosity 44.5 C.P , yield point 71 $\left(\mathrm{lb} \backslash 100 \mathrm{ft}^{2}\right)$ while the gel strength was $34\left(1 \mathrm{~b} \backslash 100 \mathrm{ft}^{2}\right)$.

The plastic viscosity values ranged (5-9) C.P* and the filtration rate values decreased gradually to $80 \mathrm{Cm}^{3} \backslash 30 \mathrm{Min}$, and remain constant at weight $2 \mathrm{gm}$ and more. The alkalinity values maintained around 13 . 


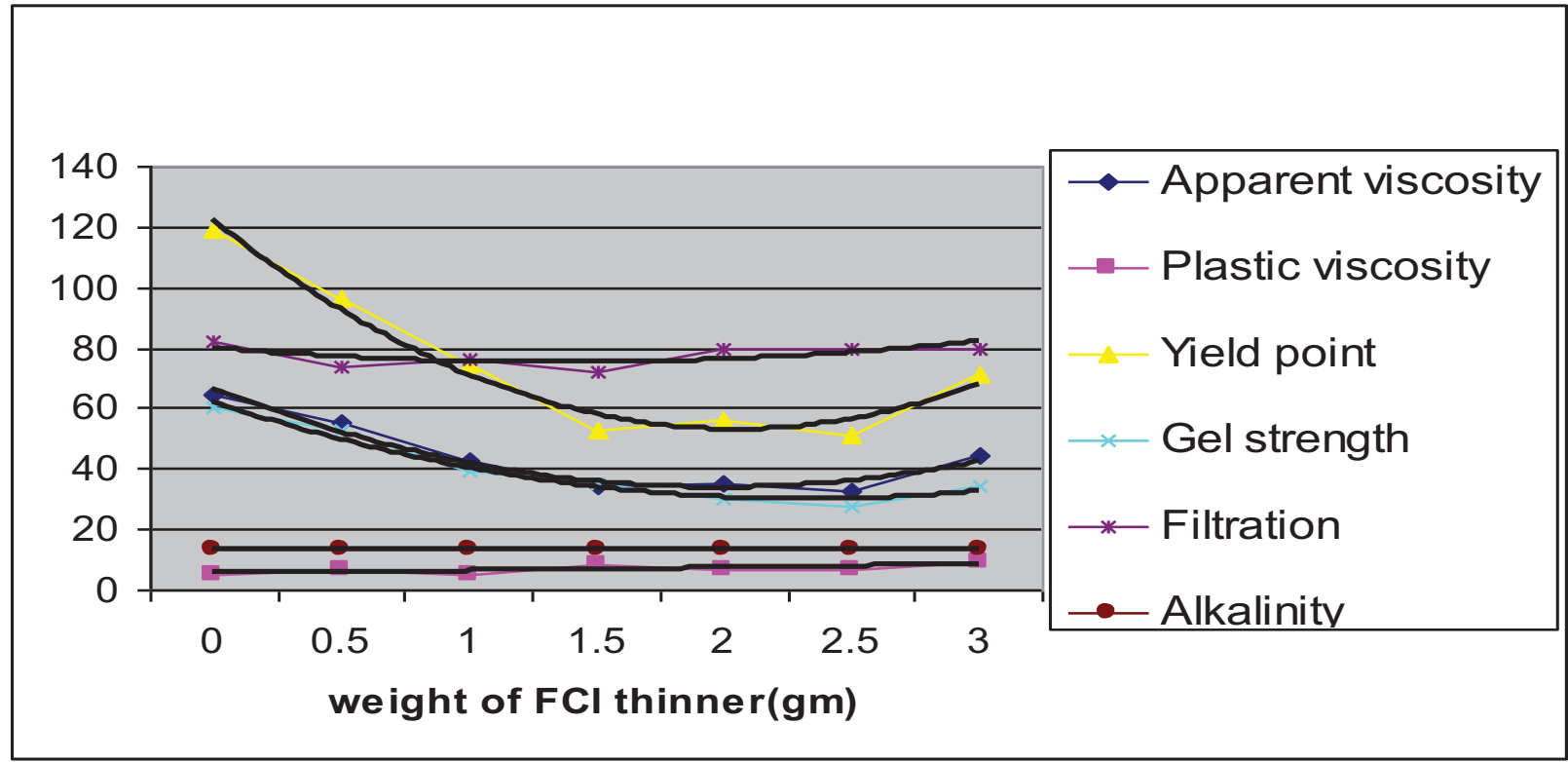

Fig.(5) Effect of FCI thinner on the rheological behavior of lime mud.

\section{B- Local thinner}

It is noticed that apparent viscosity, yield point and gel strength decreased clearly to weight 1 gm of the added thinner before they stabilized. The same behavior is concluded with the plastic viscosity before they stabilized between (3-5) C.P while filtration rate values at 1 gm are increased gradually to $100 \mathrm{~cm}^{3} \backslash 30$ Min., before they decreased to be $90 \mathrm{~cm}^{3} \backslash 30 \mathrm{Min}$. at the 3 gm., the alkalinity of filtrate is nearly around 13.0.

* The increments in plastic viscosity, yield point and gel strength values are attributed to the flocculation phenomenon.

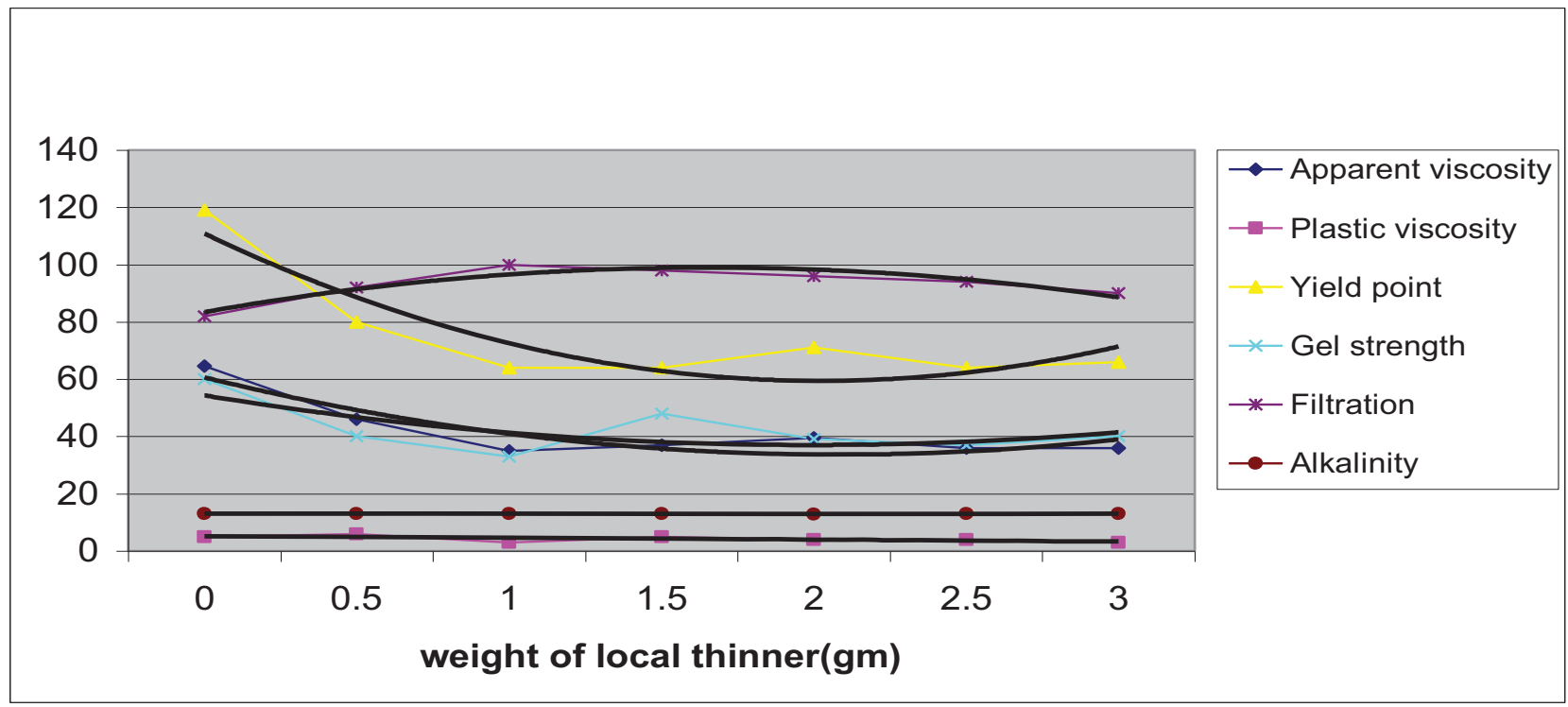

Fig.(6) Effect of local thinner on the rheological behavior of lime mud. 


\section{Conclusions}

Depending on the results obtained in this study we can conclude the following:-

1-For fresh water mud

There is an identical behavior between the $\mathrm{FCl}$ and local thinners to the weight $1 \mathrm{gm}$ of the local added thinner before their properties are stabilized. In this type of mud the FCl thinner is better than the local to certain limit.

2- For salt mud

There is an identical behavior between the $\mathrm{FCl}$ and local thinners to some degree; the local thinner works properly until to $1.5 \mathrm{gm}$ of the added thinner, while the $\mathrm{FCl}$ works to $1 \mathrm{gm}$ only. In this type of mud the local thinner is better than the $\mathrm{FCl}$ to certain limit.

3-For lime mud

There is an identical behavior between the $\mathrm{FCl}$ and local thinners to $1 \mathrm{gm}$ of the local added thinner before their properties are stabilized. In this type of mud the FCl thinner is better than the local to certain limit. 


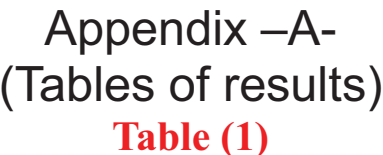

Effect of $\mathrm{FCl}$ thinner on the rheological behavior for fresh water mud

\begin{tabular}{|c|c|c|c|c|c|c|c|}
\hline Distilled water, ml & 350 & 350 & 350 & 350 & 350 & 350 & 350 \\
\hline Bentonite,gm & 22.5 & 22.5 & 22.5 & 22.5 & 22.5 & 22.5 & 22.5 \\
\hline Aged temperature, $\mathbf{F}^{0}$ & $\begin{array}{c}\text { Room } \\
\text { temperature }\end{array}$ & & & & & & \\
\hline Aged time,hrs & 24 & 24 & 24 & 24 & 24 & 24 & 24 \\
\hline gm,thinner & 0 & 0.5 & 1 & 1.5 & 2 & 2.5 & 3 \\
\hline Mixing time,min & 20 & 20 & 20 & 20 & 20 & 20 & 20 \\
\hline R600 & 63 & 52 & 39 & 36 & 29 & 22 & 21 \\
\hline R300 & 53 & 42 & 30 & 26 & 20 & 14 & 13 \\
\hline $\mathbf{R 2 0 0}$ & 48 & 37 & 27 & 23 & 16 & 11 & 9 \\
\hline R100 & 42 & 35 & 22 & 17 & 12 & 8 & 6 \\
\hline R6 & 33 & 25 & 14 & 10 & 3 & 3 & 2 \\
\hline R3 & 32 & 25 & 14 & 9 & 3 & 2 & 1 \\
\hline 10 sec.gel $\mathrm{lb} / 100 \mathrm{ft}^{2}$ & 29 & 23 & 15 & 8 & 3 & 2 & 2 \\
\hline Apparent viscosity,cp & 31.5 & 26 & 19.5 & 18 & 14.5 & 11 & 10.5 \\
\hline Plastic viscosity,cp & 10 & 10 & 9 & 10 & 9 & 8 & 9 \\
\hline Yield point $\mathrm{lb} / 100 \mathrm{ft}^{2}$ & 43 & 32 & 21 & 16 & 11 & 6 & 4 \\
\hline API filtrate loss $(30 \mathrm{~min}), \mathrm{ml}$ & 15.2 & 13.2 & 13.2 & 12.6 & 11.2 & 10.8 & 10.4 \\
\hline PH of filtrate & 9.8 & 9.44 & 9.35 & 9.13 & 8.85 & 8.53 & 8.5 \\
\hline
\end{tabular}

Table (2)

Effect of local thinner on the rheological behavior for fresh water mud

\begin{tabular}{|c|c|c|c|c|c|c|c|}
\hline Distilled water, $\mathrm{ml}$ & 350 & 350 & 350 & 350 & 350 & 350 & 350 \\
\hline Bentonite,gm & 22.5 & 22.5 & 22.5 & 22.5 & 22.5 & 22.5 & 22.5 \\
\hline Aged temperature, $\mathbf{F}^{0}$ & $\begin{array}{c}\text { Room } \\
\text { temperature }\end{array}$ & & & & & & \\
\hline Aged time,hrs & 24 & 24 & 24 & 24 & 24 & 24 & 24 \\
\hline gm,thinner & 0 & 0.5 & 1 & 1.5 & 2 & 2.5 & 3 \\
\hline Mixing time,min & 20 & 20 & 20 & 20 & 20 & 20 & 20 \\
\hline R600 & 63 & 61 & 60 & 63 & 60 & 62 & 63 \\
\hline R300 & 53 & 51 & 50 & 52 & 50 & 52 & 53 \\
\hline R200 & 48 & 47 & 47 & 49 & 48 & 49 & 49 \\
\hline R100 & 42 & 41 & 41 & 42 & 43 & 43 & 44 \\
\hline R6 & 33 & 33 & 32 & 33 & 32 & 34 & 34 \\
\hline R3 & 32 & 32 & 30 & 32 & 31 & 33 & 33 \\
\hline 10 sec.gel $\mathrm{lb} / 100 \mathrm{ft}^{2}$ & 29 & 31 & 31 & 31 & 31 & 32 & 32 \\
\hline Apparent viscosity ,cp & 31.5 & 30.5 & 30 & 31.5 & 30 & 31 & 31.5 \\
\hline Plastic viscosity,cp & 10 & 10 & 10 & 11 & 10 & 10 & 10 \\
\hline Yield point $\mathrm{lb} / 100 \mathrm{ft}^{2}$ & 43 & 41 & 40 & 41 & 40 & 42 & 43 \\
\hline API filtrate loss(30 min),ml & 15.2 & 14 & 13.2 & 13.2 & 12.4 & 12 & 11.6 \\
\hline PH of filtrate & 9.8 & 9.6 & 9.5 & 9.16 & 9.14 & 9.04 & 9 \\
\hline
\end{tabular}


Table (3)

Effect of FCl thinner on the rheological behavior for salt water mud

\begin{tabular}{|c|c|c|c|c|c|c|c|}
\hline $\begin{array}{l}\text { Sea water, } \mathrm{ml} \\
(4 \% \mathrm{Nacl})\end{array}$ & 350 & 350 & 350 & 350 & 350 & 350 & 350 \\
\hline Bentonite,gm & 22.5 & 22.5 & 22.5 & 22.5 & 22.5 & 22.5 & 22.5 \\
\hline Aged temperature, $\mathbf{F}^{0}$ & $\begin{array}{c}\text { Room } \\
\text { temperature }\end{array}$ & & & & & & \\
\hline Aged time,hrs & 24 & 24 & 24 & 24 & 24 & 24 & 24 \\
\hline gm,thinner & 0 & 0.5 & 1 & 1.5 & 2 & 2.5 & 3 \\
\hline Mixing time,min & 20 & 20 & 20 & 20 & 20 & 20 & 20 \\
\hline R600 & 42 & 31 & 32 & 38 & 42 & 42 & 36 \\
\hline R300 & 37 & 27 & 28 & 36 & 37 & 37 & 30 \\
\hline $\mathbf{R 2 0 0}$ & 36 & 25 & 27 & 35 & 35 & 35 & 28 \\
\hline R100 & 33 & 23 & 25 & 33 & 34 & 34 & 26 \\
\hline R6 & 25 & 19 & 20 & 27 & 27 & 27 & 20 \\
\hline R3 & 20 & 17 & 18 & 22 & 25 & 24 & 19 \\
\hline 10 sec.gel lb/100 ft ${ }^{2}$ & 14 & 11 & 11 & 17 & 19 & 18 & 16 \\
\hline Apparent viscosity,cp & 21 & 15.5 & 16 & 19 & 21 & 21 & 18 \\
\hline Plastic viscosity,cp & 5 & 4 & 4 & 2 & 5 & 5 & 6 \\
\hline Yield point $\mathrm{lb} / 100 \mathrm{ft}^{2}$ & 32 & 23 & 24 & 34 & 32 & 32 & 24 \\
\hline API filtrate loss(30 min),ml & 50.4 & 54 & 55.6 & 54.8 & 48.8 & 49.2 & 42.8 \\
\hline PH of filtrate & 8.9 & 8.34 & 8.34 & 8.27 & 7.9 & 7.87 & 7.73 \\
\hline
\end{tabular}

Table (4)

Effect of local thinner on the rheological behavior for salt water mud

\begin{tabular}{|c|c|c|c|c|c|c|c|}
\hline $\begin{array}{l}\text { Sea water, ml } \\
(4 \% \text { Nacl })\end{array}$ & 350 & 350 & 350 & 350 & 350 & 350 & 350 \\
\hline Bentonite,gm & 22.5 & 22.5 & 22.5 & 22.5 & 22.5 & 22.5 & 22.5 \\
\hline Aged temperature, $F^{0}$ & $\begin{array}{c}\text { Room } \\
\text { temperature }\end{array}$ & & & & & & \\
\hline Aged time,hrs & 24 & 24 & 24 & 24 & 24 & 24 & 24 \\
\hline gm,thinner & 0 & 0.5 & 1 & 1.5 & 2 & 2.5 & 3 \\
\hline Mixing time,min & 20 & 20 & 20 & 20 & 20 & 20 & 20 \\
\hline R600 & 42 & 33 & 31 & 31 & 34 & 34 & 34 \\
\hline R300 & 37 & 28 & 28 & 27 & 30 & 29 & 30 \\
\hline $\mathbf{R 2 0 0}$ & 36 & 27 & 27 & 26 & 28 & 27 & 28 \\
\hline R100 & 33 & 26 & 24 & 24 & 25 & 25 & 26 \\
\hline R6 & 25 & 20 & 19 & 19 & 19 & 19 & 20 \\
\hline R3 & 20 & 18 & 17 & 18 & 18 & 17 & 18 \\
\hline 10 sec.gel lb/100 ft ${ }^{2}$ & 14 & 14 & 14 & 14 & 14 & 12 & 12 \\
\hline Apparent viscosity,cp & 21 & 16.5 & 15.5 & 15.5 & 17 & 17 & 17 \\
\hline Plastic viscosity,cp & 5 & 3 & 3 & 4 & 4 & 5 & 4 \\
\hline Yield point $\mathrm{lb} / \mathbf{1 0 0} \mathrm{ft}^{2}$ & 32 & 25 & 25 & 23 & 26 & 24 & 26 \\
\hline API filtrate loss(30 min),ml & 50.4 & 50 & 47.2 & 46.4 & 46 & 47.6 & 45.4 \\
\hline PH of filtrate & 8.9 & 8.6 & 8.75 & 8.8 & 8.47 & 8.14 & 8.24 \\
\hline
\end{tabular}


Table (5)

Effect of FCl thinner on the rheological behavior for lime mud

\begin{tabular}{|c|c|c|c|c|c|c|c|}
\hline Tap water, $\mathrm{ml}$ & 350 & 350 & 350 & 350 & 350 & 350 & 350 \\
\hline Bentonite,gm & 22.5 & 22.5 & 22.5 & 22.5 & 22.5 & 22.5 & 22.5 \\
\hline Aged temperature, $\mathrm{C}^{0}$ & $\begin{array}{c}\text { Room } \\
\text { temperature }\end{array}$ & & & & & & \\
\hline gm,thinner & 0 & 0.5 & 1 & 1.5 & 2 & 2.5 & 3 \\
\hline Lime(Cao)gm & 5 & 5 & 5 & 5 & 5 & 5 & 5 \\
\hline Mixing time,min & 20 & 20 & 20 & 20 & 20 & 20 & 20 \\
\hline R300 & 124 & 103 & 80 & 61 & 63 & 58 & 80 \\
\hline R200 & 119 & 99 & 70 & 58 & 61 & 55 & 76 \\
\hline R100 & 111 & 93 & 65 & 54 & 58 & 51 & 70 \\
\hline R6 & 69 & 63 & 59 & 42 & 45 & 40 & 44 \\
\hline R3 & 62 & 54 & 40 & 37 & 36 & 32 & 43 \\
\hline 10 sec.gel lb/100 $\mathrm{ft}^{2}$ & 60 & 53 & 39 & 35 & 30 & 28 & 34 \\
\hline Yield point $\mathrm{lb} / 100 \mathrm{ft}^{2}$ & 119 & 96 & 75 & 53 & 56 & 51 & 71 \\
\hline API filtrate loss $(30 \mathrm{~min}), \mathrm{ml}$ & 82 & 74 & 76 & 72 & 80 & 80 & 80 \\
\hline PH of filtrate & 13.12 & 13.3 & 13.2 & 13.1 & 13.3 & 13.3 & 13.00 \\
\hline
\end{tabular}

Table (6)

Effect of local thinner on the rheological behavior for lime mud

\begin{tabular}{|c|c|c|c|c|c|c|c|}
\hline Tap water, ml & 350 & 350 & 350 & 350 & 350 & 350 & 350 \\
\hline Bentonite,gm & 22.5 & 22.5 & 22.5 & 22.5 & 22.5 & 22.5 & 22.5 \\
\hline Aged temperature, $\mathrm{C}^{0}$ & $\begin{array}{c}\text { Room } \\
\text { temperature }\end{array}$ & & & & & & \\
\hline Aged time,hrs & 24 & 24 & 24 & 24 & 24 & 24 & 24 \\
\hline gm,thinner & 0 & 0.5 & 1 & 1.5 & 2 & 2.5 & 3 \\
\hline Lime(Cao)gm & 5 & 5 & 5 & 5 & 5 & 5 & 5 \\
\hline Mixing time,min & 20 & 20 & 20 & 20 & 20 & 20 & 20 \\
\hline R600 & 129 & 92 & 70 & 74 & 79 & 72 & 72 \\
\hline R300 & 124 & 86 & 67 & 69 & 75 & 68 & 69 \\
\hline R200 & 119 & 83 & 66 & 67 & 71 & 67 & 67 \\
\hline R100 & 111 & 79 & 64 & 65 & 67 & 66 & 65 \\
\hline R6 & 69 & 56 & 48 & 55 & 54 & 52 & 52 \\
\hline R3 & 62 & 46 & 39 & 49 & 45 & 44 & 44 \\
\hline 10 sec.gel $\mathrm{lb} / 100 \mathrm{ft}^{2}$ & 60 & 40 & 33 & 48 & 39 & 37 & 40 \\
\hline Apparent viscosity,cp & 64.5 & 46 & 35 & 37 & 39.5 & 36 & 36 \\
\hline Plastic viscosity,cp & 5 & 6 & 3 & 5 & 4 & 4 & 3 \\
\hline Yield point $\mathrm{lb} / \mathbf{1 0 0} \mathrm{ft}^{2}$ & 119 & 80 & 64 & 64 & 71 & 64 & 66 \\
\hline API filtrate loss(30 min),ml & 82 & 92 & 100 & 98 & 96 & 94 & 90 \\
\hline PH of filtrate & 13.12 & 12.97 & 12.98 & 13.0 & 12.88 & 12.96 & 12.96 \\
\hline
\end{tabular}


 \\ Laboratory tests for local thinner)}

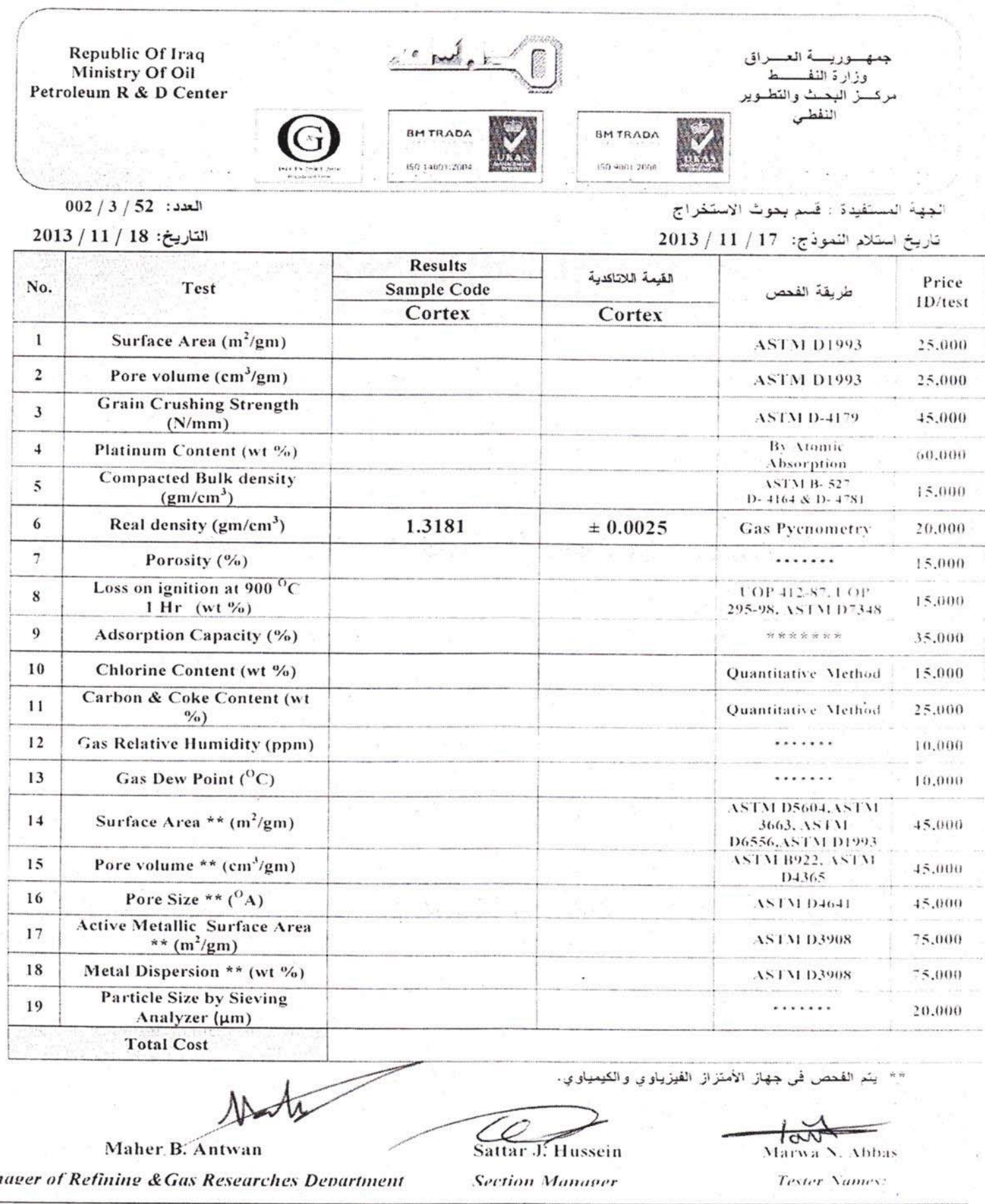


2- Detection of both cooper and iron ratio in the local thinner by ultra violet test.

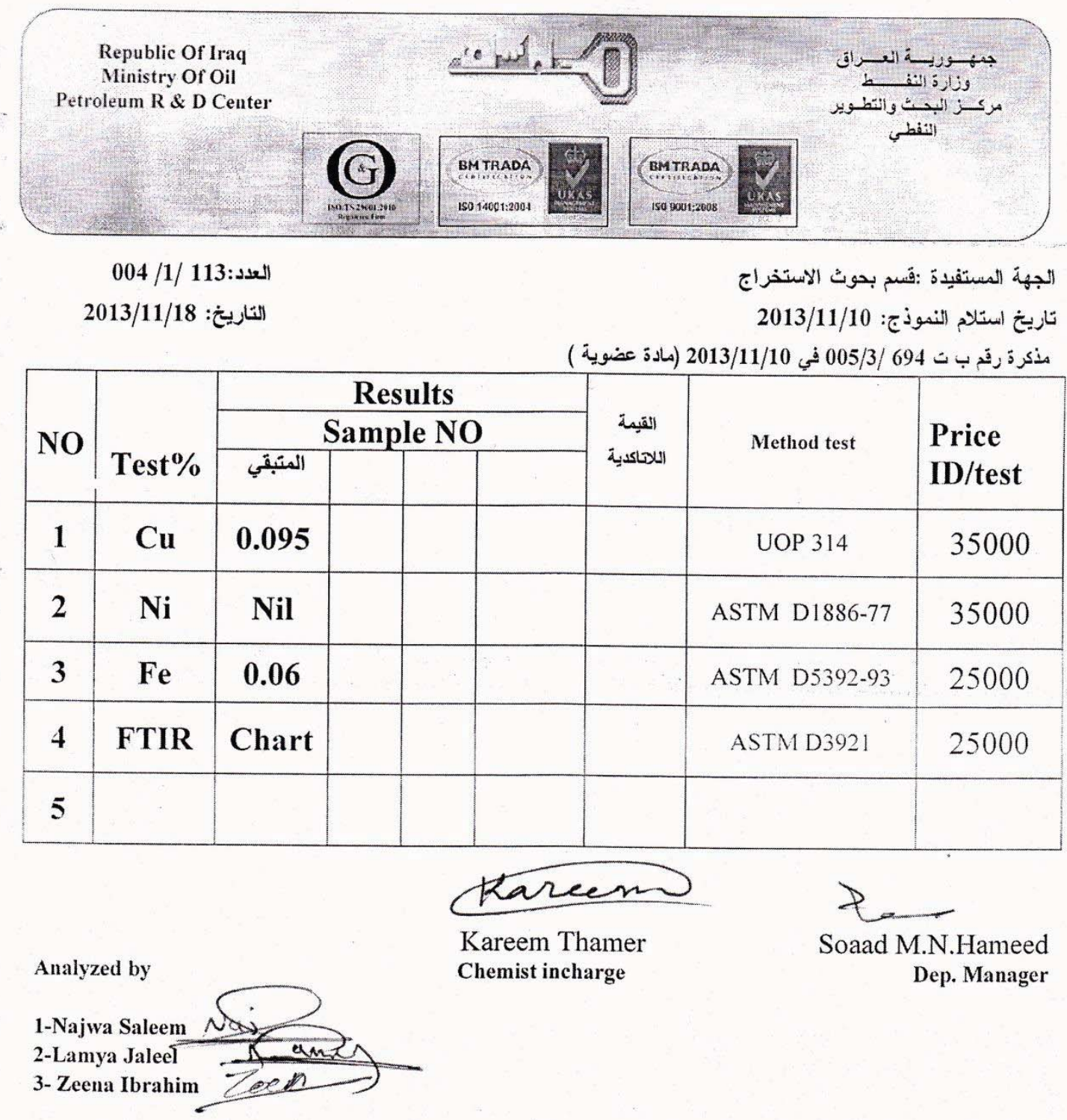

Address : Baghdad/Waziriyah /near the Petroleum Institute

Tel : $07901356910 / 07901356921$

Email : prdc2004@yahoo.com
العنوان : بغداد - المزيرية / قرب معهد النفط

07901356910 / التهاتف : 07901356921

prdc2004@yahoo.com : البريد الاككتروني : 
3-Fourier transform infrared test

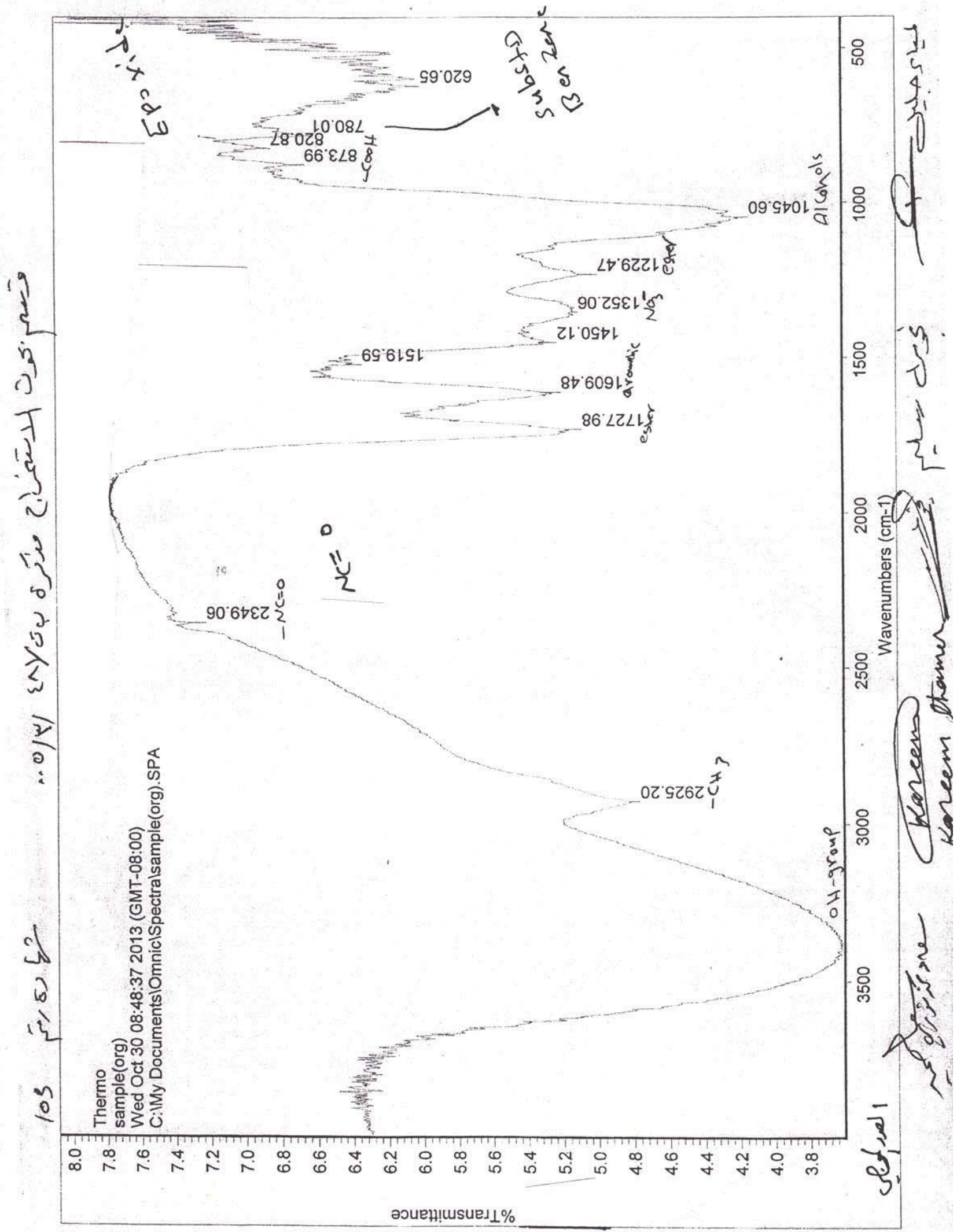




\section{$\underline{\text { References }}$}

1. J.P Nguyen "Drilling, oil and gas field development techniques "Edition TECHNIP, Paris, 1996.

2. N.Eversand and W.smith,"The analysis of Drugs and chemicals Charles", Griffen company Limited, London 1955, Pages 396 and 303.

3. N.W, Hussein, and Abid Aljabar, F.T"Drilling rig hydraulics",Hand Book, Baghadad Oil Training Institute, 2003.

4. Rogers, G, D." Composition and properties of drilling fluids"; Gulf publishing company .USA 4th edition, 1979, pages 5,565,567,568,570,574.

5. S.Hellborn, J.E.weleh and L.N Owen"Thorpes dictionary of applied chemistry ", Long mans Green Co.LTD, London. Fourth edition 1965, volume IV page 1, volume IX pages390-405

6. Tawfik, A, K and Abid Aljabar, T, F "Oil and gas well drilling techniques",Book, first part, Baghdad oil training institute, 1987. 